\title{
Comparison of non-invasive to invasive oxygenation ratios for diagnosing acute respiratory distress syndrome following coronary artery bypass graft surgery: a prospective derivation-validation cohort study
}

Farshid R. Bashar ${ }^{1}$, Amir Vahedian-Azimi ${ }^{2}$, Behrooz Farzanegan ${ }^{3}$, Reza Goharani ${ }^{4}$, Seyedpouzhia Shojaei ${ }^{4}$, Sevak Hatamian ${ }^{5}$, Seyed M. M. Mosavinasab ${ }^{6}$, Masoum Khoshfetrat ${ }^{7}$, Mohammad A. K. Khatir ${ }^{8}$, Anna Tomdio ${ }^{9}$, Andrew C. Miller ${ }^{10^{*}}$ (i) and for the MORZAK Collaborative

\begin{abstract}
Objective: To determine if non-invasive oxygenation indices, namely peripheral capillary oxygen saturation $\left(\mathrm{S}_{\mathrm{p}} \mathrm{O}_{2}\right) /$ fraction of inspired oxygen $\left(\mathrm{F}_{i} \mathrm{O}_{2}\right)$ and partial pressure of alveolar oxygen $\left(\mathrm{P}_{\mathrm{A}} \mathrm{O}_{2}\right) / \mathrm{F}_{i} \mathrm{O}_{2}$ may be used as effective surrogates for the partial pressure of arterial oxygen $\left(\mathrm{P}_{2} \mathrm{O}_{2}\right) / \mathrm{F}_{\mathrm{i}} \mathrm{O}_{2}$. Also, to determine the $\mathrm{S}_{\mathrm{p}} \mathrm{O}_{2} / \mathrm{F}_{i} \mathrm{O}_{2}$ and $\mathrm{P}_{\mathrm{A}} \mathrm{O}_{2} / \mathrm{F}_{i} \mathrm{O}_{2}$ values that correspond to $\mathrm{P}_{\mathrm{a}} \mathrm{O}_{2} / \mathrm{F}_{i} \mathrm{O}_{2}$ thresholds for identifying acute respiratory distress syndrome (ARDS) in patients following coronary artery bypass graft (CABG) surgery.
\end{abstract}

Methods: A prospective derivation-validation cohort study in the Open-Heart ICU of an academic teaching hospital. Recorded variables included patient demographics, ventilator settings, chest radiograph results, and $\mathrm{SpO}_{2}, \mathrm{P}_{2} \mathrm{O}_{2}$, $\mathrm{P}_{\mathrm{A}} \mathrm{O}_{2}, \mathrm{~S}_{\mathrm{a}} \mathrm{O}_{2}$, and $\mathrm{F}_{\mathrm{i}} \mathrm{O}_{2}$. Linear regression modeling was used to quantify the relationship between indices. Receiver operating characteristic (ROC) curves were used to determine the sensitivity and specificity of the threshold values.

Results: One-hundred seventy-five patients were enrolled in the derivation cohort, and 358 in the validation cohort. The $\mathrm{S}_{\mathrm{P}} \mathrm{O}_{2} / \mathrm{F}_{\mathrm{i}} \mathrm{O}_{2}$ and $\mathrm{P}_{\mathrm{A}} \mathrm{O}_{2} / \mathrm{F}_{\mathrm{i}} \mathrm{O}_{2}$ ratios could be predicted well from $\mathrm{P}_{\mathrm{a}} \mathrm{O}_{2} / \mathrm{F}_{\mathrm{i}} \mathrm{O}_{2}$, described by the linear regression models $\mathrm{S}_{\mathrm{P}} \mathrm{O}_{2} / \mathrm{F}_{\mathrm{i}} \mathrm{O}_{2}=71.149+0.8 \mathrm{PF}$ and $\mathrm{P}_{\mathrm{A}} \mathrm{O}_{2} / \mathrm{F}_{\mathrm{i}} \mathrm{O}_{2}=38.098+2.312 \mathrm{PF}$, respectively. According to the linear regression equation, a $\mathrm{P}_{2} \mathrm{O}_{2} / \mathrm{F}_{i} \mathrm{O}_{2}$ ratio of 300 equaled an $\mathrm{S}_{\mathrm{P}} \mathrm{O}_{2} / \mathrm{F}_{\mathrm{O}} \mathrm{O}_{2}$ ratio of $311\left(\mathrm{R}^{2} 0.857, \mathrm{~F} 1035.742,<0.0001\right)$ and a $\mathrm{P}_{\mathrm{A}} \mathrm{O}_{2} / \mathrm{F}_{i} \mathrm{O}_{2}$ ratio of $732\left(\mathrm{R}^{2} 0.576, \mathrm{~F} 234.887,<0.0001\right)$. The $\mathrm{S}_{P} \mathrm{O}_{2} / \mathrm{F}_{i} \mathrm{O}_{2}$ threshold of 311 had $90 \%$ sensitivity, $80 \%$ specificity, LR+ 4.50, LR- 0.13, PPV 98, and NPV 42.1 for the diagnosis of mild ARDS. The $\mathrm{P}_{\mathrm{A}} \mathrm{O}_{2} / \mathrm{F}_{\mathrm{i}} \mathrm{O}_{2}$ threshold of 732 had 86\% sensitivity, 90\% specificity, LR+ 8.45, LR- 0.16, PPV 98.9, and NPV 36 for the diagnosis of mild ARDS. $\mathrm{S}_{\mathrm{P}} \mathrm{O}_{2} /$ $\mathrm{F}_{\mathrm{i}} \mathrm{O}_{2}$ had excellent discrimination ability for mild ARDS ( $\mathrm{AUC} \pm \mathrm{SE}=0.92 \pm 0.017 ; 95 \% \mathrm{Cl} 0.889$ to 0.947 ) as did $\mathrm{P}_{\mathrm{A}} \mathrm{O}_{2} /$ $\mathrm{F}_{\mathrm{i}} \mathrm{O}_{2}(\mathrm{AUC} \pm \mathrm{SE}=0.915 \pm 0.018 ; 95 \% \mathrm{Cl} 0.881$ to 0.942 ).

(Continued on next page)

\footnotetext{
*Correspondence: Taqwa1@gmail.com; MillerAndr17@ECU.edu

${ }^{10}$ Department of Emergency Medicine, Vident Medical Center, East Carolina

University Brody School of Medicine, 600 Moye Blvd, Greenville, NC 27834,

USA

Full list of author information is available at the end of the article
}

(c) The Author(s). 2018 Open Access This article is distributed under the terms of the Creative Commons Attribution 4.0 International License (http://creativecommons.org/licenses/by/4.0/), which permits unrestricted use, distribution, and reproduction in any medium, provided you give appropriate credit to the original author(s) and the source, provide a link to the Creative Commons license, and indicate if changes were made. The Creative Commons Public Domain Dedication waiver (http://creativecommons.org/publicdomain/zero/1.0/) applies to the data made available in this article, unless otherwise stated. 
(Continued from previous page)

Conclusions: $\mathrm{P}_{a} \mathrm{O}_{2}$ and $\mathrm{S}_{\mathrm{a}} \mathrm{O}_{2}$ correlated in the diagnosis of $A R D S$, with a $\mathrm{P}_{a} \mathrm{O}_{2} / \mathrm{F}_{i} \mathrm{O}_{2}$ of 300 correlating to an $\mathrm{S}_{\mathrm{p}} \mathrm{O}_{2} /$ $\mathrm{F}_{\mathrm{i}} \mathrm{O}_{2}$ of 311 (Sensitivity 90\%, Specificity 80\%). The $\mathrm{S}_{\mathrm{p}} \mathrm{O}_{2} / \mathrm{F}_{\mathrm{i}} \mathrm{O}_{2}$ ratio may allow for early real-time rapid identification of ARDS, while decreasing the cost, phlebotomy, blood loss, pain, skin breaks, and vascular punctures associated with serial arterial blood gas measurements.

Keywords: Coronary artery bypass graft surgery, Acute respiratory distress syndrome, Oxygenation indices, Ratio of arterial oxygen partial pressure to fractional inspired oxygen, Ratio of peripheral capillary oxygen saturation to fractional inspired oxygen, Ratio of partial pressure of alveolar oxygen to fractional inspired oxygen

\section{Background}

Circulatory and cardiovascular diseases (CVD) remain the leading cause of death globally [1]. In 2013, 17 million (32\%) of NCD deaths were attributable to CVD, a number expected to rise to 11.1 million by 2020 [3], and > 23.6 million by 2030 [3-5]. Coronary artery disease (CAD), the most common type of CVD, is the leading cause of death, morbidity and decline in quality-of-life (QoL) globally, and is predicted to remain so for the next 20 years [2, 3].

Coronary artery bypass graft (CABG) surgery is a common revascularization technique used to re-establish or improve flow to under-perfused regions of the heart. Predicting outcomes in postoperative cardiac surgery patients has proven to be an extremely difficult task. The severity-of-illness scoring systems that are commonly used in medical ICUs have not been very useful in predicting death in these patients, as high scores are often not associated with poor outcome [6-8]. This may in part be due to our ability to normalize physiology by means of pharmacologic and/or mechanical support. The reported incidence of acute respiratory distress syndrome (ARDS) in patients undergoing open heart surgery with cardiopulmonary bypass (CPB) is $0.4-2.5 \%$, with an associated mortality rate up to $68.4 \%$ [9-12]. The current ARDS definition (Berlin Criteria) requires arterial blood gas (ABG) measurement to monitor the partial pressure of $\mathrm{O}_{2}$ in arterial blood $\left(\mathrm{P}_{\mathrm{a}} \mathrm{O}_{2}\right)$ and includes a minimum PEEP value to account for the effect of mechanical ventilator settings on $\mathrm{P}_{\mathrm{a}} \mathrm{O}_{2} / \mathrm{F}_{\mathrm{i}} \mathrm{O}_{2}$ [13]. However, the Berlin definition is only slightly better than its predecessor for ARDS prognostication (receiver operating characteristic [ROC] area under the curve [AUC], 0.577 vs 0.536 ). This may be partially related to the dependence of both definitions on $\mathrm{P}_{\mathrm{a}} \mathrm{O}_{2} / \mathrm{F}_{\mathrm{i}} \mathrm{O}_{2}$ as the primary measure of ARDS severity. Multiple studies have shown that $\mathrm{P}_{\mathrm{a}} \mathrm{O}_{2} / \mathrm{F}_{\mathrm{i}} \mathrm{O}_{2}$ is not an independent mortality predictor in ARDS [14-16]. The $\mathrm{P}_{\mathrm{a}} \mathrm{O}_{2}$ / $\mathrm{F}_{\mathrm{i}} \mathrm{O}_{2}$ does not reflect other aspects of lung injury severity such as mechanical ventilation settings, changes in lung compliance, and pulmonary shunt [17]. Additionally, concerns about anemia, excessive phlebotomy, and a movement to minimally invasive approaches have led to fewer ABG measurements in critically ill patients [18]. We investigated the performance of the peripheral capillary oxygen saturation $\left(\mathrm{S}_{\mathrm{p}} \mathrm{O}_{2}\right) / \mathrm{F}_{\mathrm{i}} \mathrm{O}_{2}$ and partial pressure of alveolar $\mathrm{O}_{2}\left(\mathrm{P}_{\mathrm{A}} \mathrm{O}_{2}\right) / \mathrm{F}_{\mathrm{i}} \mathrm{O}_{2}$ oxygenation indices to $\mathrm{P}_{\mathrm{a}} \mathrm{O}_{2} / \mathrm{F}_{\mathrm{i}} \mathrm{O}_{2}$ $(\mathrm{P} / \mathrm{F})$ in identifying post-operative ARDS in CABG patients. Additionally, we seek to determine the threshold values for $\mathrm{S}_{\mathrm{p}} \mathrm{O}_{2} / \mathrm{F}_{\mathrm{i}} \mathrm{O}_{2}(\mathrm{~S} / \mathrm{F})$ and $\mathrm{P}_{\mathrm{A}} \mathrm{O}_{2} / \mathrm{F}_{\mathrm{i}} \mathrm{O}_{2}\left(\mathrm{P}_{\mathrm{A}} / \mathrm{F}\right)$ that correlate with $\mathrm{P} / \mathrm{F}$ ratios consistent with $\mathrm{ARDS}$ (mild 201300; moderate 101-200; severe $\leq 100 \mathrm{mmHg}$ ).

\section{Methods \\ Study design and setting}

We conducted a prospective derivation-validation cohort study in the Open-Heart ICU of an academic teaching hospital from October 1, 2011 to April 31, 2012. All patients undergoing $C A B G$ surgery during this period were screened for enrollment. The study protocol was approved by the local institutional investigative review board. All study parts were reviewed according to the Strengthening the Reporting of Observational Studies in Epidemiology (STROBE) Statement: guidelines for reporting observational studies [19].

Patients were eligible for study participation if: (1) age $\geq$ 18 years, (2) full code-status, (3) first CABG surgery, (4) non-emergency CABG Surgery, (5) left ventricular ejection fraction $\geq 30 \%$, and (6) informed consent provided by the patient, legal guardian, or healthcare surrogate.

Patients were excluded for: (1) post-operative hemorrhage $>300 \mathrm{ml}$ in the first hour post-op with need for Surgical intervention; (2) unscheduled return to surgery; (3) pacemaker dependence; (4) history of prior CABG; (5) emergency CABG; (6) left ventricular ejection fraction (LVEF) < 30\%; (7) psychiatric comorbidity; or (8) excessive sedation requirements. Sedation levels were determined in accordance with published recommendations [20-22].

Recorded variables included patient demographics, ventilator settings, chest radiograph results, and $\mathrm{S}_{\mathrm{P}} \mathrm{O}_{2}$, $\mathrm{P}_{\mathrm{a}} \mathrm{O}_{2}, \mathrm{~F}_{\mathrm{i}} \mathrm{O}_{2}$ and $\mathrm{S}_{\mathrm{a}} \mathrm{O}_{2}$. These latter were used to calculate $\mathrm{S} / \mathrm{F}, \mathrm{P}_{\mathrm{A}} / \mathrm{F}$ and $\mathrm{P} / \mathrm{F}$ ratios.

\section{Data sources}

\section{Derivation group}

Corresponding measurements of $\mathrm{S}_{\mathrm{P}} \mathrm{O}_{2}$ and $\mathrm{P}_{\mathrm{a}} \mathrm{O}_{2}$ from patients $(n=175)$ undergoing CABG surgery were utilized to establish the relationship between $\mathrm{S} / \mathrm{F}, \mathrm{P}_{\mathrm{A}} / \mathrm{F}$ and $\mathrm{P} / \mathrm{F}$ ratios. All mechanical ventilation settings were 
performed by three intensivists, and settings were consistent with routine standard-of-care including low $V_{T}$ ventilation strategies. All patients were ventilated using Dräger Evita ${ }^{\circ}$ XL or Evita ${ }^{\circ} 4$ ventilators (Dräeger Medical, Inc., Lubeck, Germany).

$\mathrm{S}_{\mathrm{P}} \mathrm{O}_{2}, \mathrm{P}_{\mathrm{a}} \mathrm{O}_{2}$, and $\mathrm{F}_{\mathrm{i}} \mathrm{O}_{2}$ were measured once per patient upon study enrollment, and $\mathrm{S}_{\mathrm{P}} \mathrm{O}_{2}$ was recorded at the time of ABG sampling. In rare cases when this was not possible, the $\mathrm{S}_{\mathrm{a}} \mathrm{O}_{2}$ measurement closest temporally to the $\mathrm{S}_{\mathrm{P}} \mathrm{O}_{2}$ value was utilized. To optimize $\mathrm{S}_{\mathrm{P}} \mathrm{O}_{2}$ measurements, investigators utilized optimal patient and sensor position, ensured sensor cleanliness, and used only measurements with satisfactory waveforms. No position changes or endobronchial suctioning was performed within 10 min of measurement, and no invasive procedures or ventilator changes were performed within 30 min of measurement [12]. $\mathrm{S}_{\mathrm{P}} \mathrm{O}_{2}$ was observed for a minimum of $1 \mathrm{~min}$ before the value was recorded. Like other studies, measurements with $\mathrm{S}_{\mathrm{P}} \mathrm{O}_{2}>97 \%$ were excluded from analysis because the oxyhemoglobin dissociation curve is flat above these levels [18].

\section{Validation group}

Corresponding measurements of $\mathrm{S}_{\mathrm{P}} \mathrm{O}_{2}$ and $\mathrm{P}_{\mathrm{a}} \mathrm{O}_{2}$ from patients undergoing CABG surgery $(n=358)$ were used to establish the relationship between $\mathrm{S} / \mathrm{F}, \mathrm{P}_{\mathrm{A}} / \mathrm{F}$ and $\mathrm{P} / \mathrm{F}$ ratios. The inclusion, exclusion and mechanical ventilation settings in the validated study were like the derivation group. Moreover, $\mathrm{ABG}$ measurements and $\mathrm{S}_{\mathrm{P}} \mathrm{O}_{2}$ data were collected at similar time points using methods like the derivation data set.

\section{Statistical analysis}

\section{Sample size}

The sample sizes were determined using data obtained from a pilot investigation (unpublished): derivation $(n=$ $30)$, validation $(n=50)$. Calculations were performed using G*Power version 3.0.10 (Universität Düsseldorf, Germany; available online at http://www.psycho.uni-duesseldorf.de/abteilungen/aap/gpower3/) [14, 15]. Calculations were performed for the variable $\mathrm{P} / \mathrm{F}$ ratio, with an effect size of 0.3 . With an alpha level of $5 \%$, a confidence level of $95 \%$, a power of $90 \%$, and anticipated attrition of $10 \%$, sample sizes of at least 150 and 300 patients were needed in the derivation and validation groups respectively.

\section{Data analysis}

Normally distributed continuous variables are expressed as the means \pm standard deviation (SD). Normally distributed continuous variables were compared using the $t$-test. Categorical variables were compared using the Chi-Square $\left(x^{2}\right)$ and Fisher's Exact tests as appropriate. The correlation between $\mathrm{S} / \mathrm{F}, \mathrm{P}_{\mathrm{A}} / \mathrm{F}$ and $\mathrm{P} / \mathrm{F}$ ratios were analyzed using Pearson correlation analysis. Linear regression modeling was utilized to compare the relationship between $\mathrm{S} /$ $\mathrm{F}, \mathrm{P}_{\mathrm{A}} / \mathrm{F}$ and $\mathrm{P} / \mathrm{F}$ ratios. ROC curves were plotted to determine the prognostic values of the $\mathrm{S} / \mathrm{F}$ and $\mathrm{P}_{\mathrm{A}} / \mathrm{F}$ threshold values correlating with $\mathrm{P} / \mathrm{F} \leq 300$. For each $\mathrm{ROC}$ curve analysis, sensitivity, specificity, positive and negative predictive values (PPV and NPV), positive and negative likelihood ratios (LR+ and LR-), and probabilities for having a good surrogate when test is either positive or negative were used to predict the outcome (having good surrogate) in the validation data set.

The Hanley and McNeil method was used to calculate the AUC for each ratio, following which the AUCs were compared using methods that we have previously published [16]. In all analyses, $P<0.05$ was considered significant. All analyses were performed using $\mathrm{IBM}^{\circ} \mathrm{SPSS}^{\circ}$ v23.0 (IBM Corp., Armonk, NY), STATA 10 (Stata Corp. LLC, College Station, Texas, USA), and GraphPad Prism 5๑ (Graph Pad Software Inc., La Jolla, CA).

\section{Analysis of the derivation data set}

Scatter plots of $\mathrm{S} / \mathrm{F}$ and $\mathrm{P}_{\mathrm{A}} / \mathrm{F}$ vs $\mathrm{P} / \mathrm{F}$ ratios were utilized to determine the linear relationship between the three measurements. A linear regression model was then used to quantify the best regression line. The equation for this regression line was employed to determine the threshold values for $S / F$ and $P_{A} / F$ ratio that correlate with $P / F$ ratios consistent with ARDS $(\mathrm{P} / \mathrm{F} \leq 300)$. The $(\mathrm{S} / \mathrm{F}) /(\mathrm{P} / \mathrm{F})$ and $\left(\mathrm{P}_{\mathrm{A}} / \mathrm{F}\right) /(\mathrm{P} / \mathrm{F})$ ratios were plotted against $\mathrm{F}_{\mathrm{i}} \mathrm{O}_{2}$ and $\mathrm{S}_{\mathrm{P}} \mathrm{O}_{2}$ to assess the effect of each on the relationship. ROC curves were plotted to assess the degree of discrimination between $\mathrm{S} / \mathrm{F}$ and $\mathrm{P}_{\mathrm{A}} / \mathrm{F}$ with $\mathrm{P} / \mathrm{F}$ ratios and to slightly adjust the $S / F$ and $\mathrm{P}_{\mathrm{A}} / \mathrm{F}$ ratio threshold values for ARDS to optimize the sensitivity and specificity.

\section{Analysis of the validation data set}

Linear regression modeling was utilized to quantify the relationship between $S / F, P_{A} / F$ and $P / F$ ratios in the validation data set. ROC curves were plotted to determine the sensitivity and specificity of the threshold values derived from the derivation data set for ARDS, with the AUC calculated to assess the degree of discrimination between the ratios.

\section{Results}

A total of 729 eligible patients were screened for the study. See Figure 1 for the patient flow diagram. Fifty-eight did not meet inclusion criteria. Six-hundred Seventy-one patients consented to participate in the derivation $(n=244)$ and validation $(n=427)$ cohorts. Eighty-seven subjects died (derivation 42, validation 45), 51 were lost to follow-up (derivation 27 , validation 24), and 533 were analyzed (derivation 175 , validation 358). There were 18 (derivation 7 , validation 11) instances where the $\mathrm{S}_{\mathrm{P}} \mathrm{O}_{2}$ and $\mathrm{ABG}$ could not be sampled at 


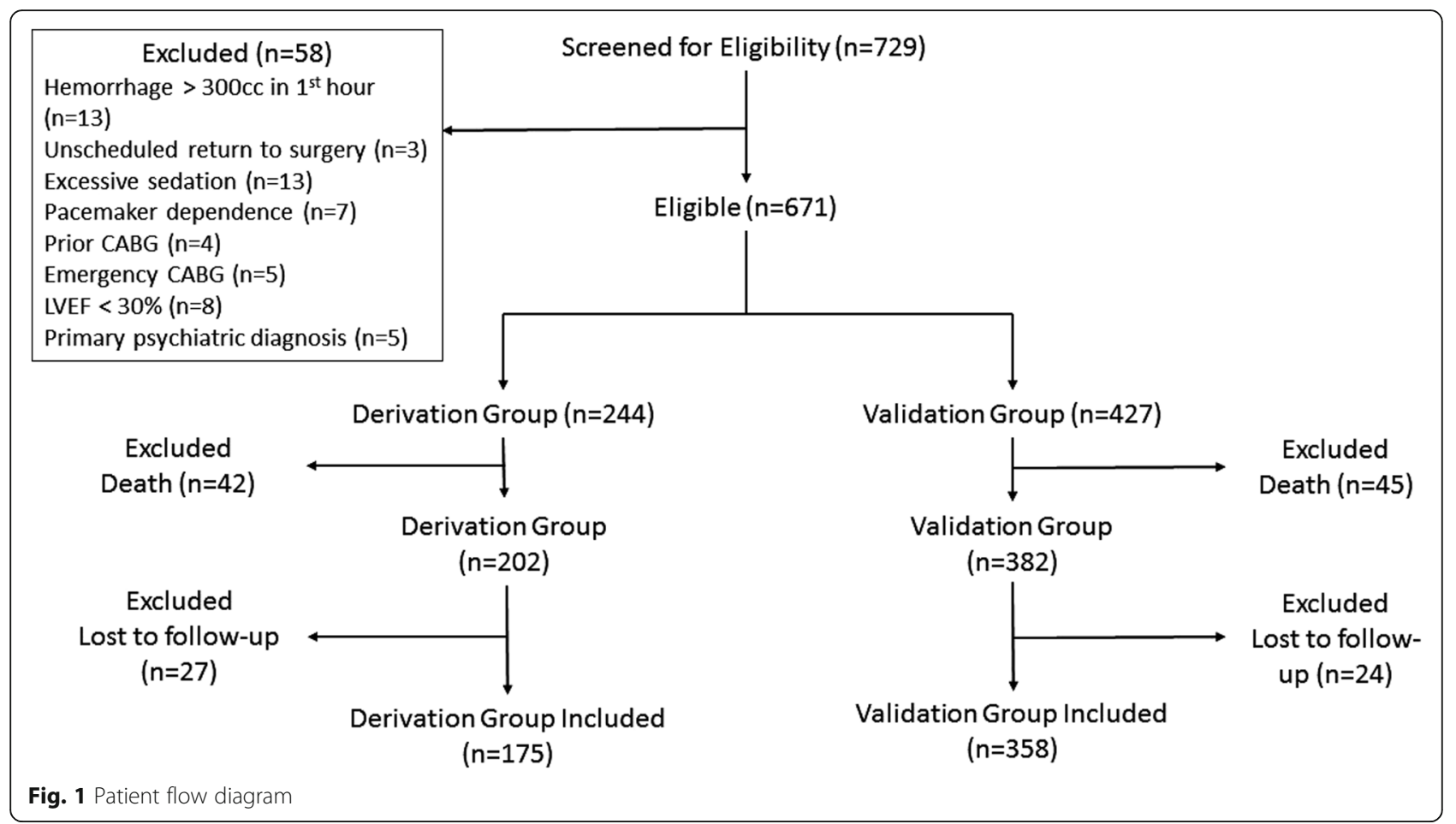

the same time, in which case the nearest $\mathrm{S}_{\mathrm{P}} \mathrm{O}_{2}$ was used (all within $30 \mathrm{~min}$ ). Patient demographics, clinical features, and physiologic respiratory variables are summarized in Table 1 . A total of 20 (28.2\%) patients were ventilated during cardiopulmonary bypass. The mean pre-op LVEF was $47.75 \pm$ $7.87 \%\left(\mathrm{P} / \mathrm{F}=48.96 \pm 8.60, \mathrm{~S} / \mathrm{F}=46.04 \pm 7.80, \mathrm{P}_{\mathrm{A}} / \mathrm{F}=48.26 \pm\right.$
7.17; $p=0.414)$. Subjects were transfused a mean of $2.06 \pm$ 0.79 units of packed red cells (P/F mean $=1.92 \pm 0.83, \mathrm{~S} / \mathrm{F} n$ $\left.=2.29 \pm 0.75, \mathrm{P}_{\mathrm{A}} / \mathrm{F} n=1.96 \pm 0.77 ; p=0.20\right)$, of which 15 (21.1\%) were allogeneic $(\mathrm{P} / \mathrm{F}=5(20.8 \%), \mathrm{S} / \mathrm{F}=5(20.8 \%)$, $\left.\mathrm{P}_{\mathrm{A}} / \mathrm{F}=5(21.7 \%) ; p=0.996\right)$. Six $(8.5 \%)$ received inotropes $\left(\mathrm{P} / \mathrm{F}=3\right.$ (12.5\%), $\mathrm{S} / \mathrm{F}=2$ (8.3\%), $\left.\mathrm{P}_{\mathrm{A}} / \mathrm{F}=1(4.3 \%) ; p=0.604\right)$.

Table 1 Demographic and clinical data

\begin{tabular}{|c|c|c|c|c|}
\hline Variables & Total & Derivation group & Validation group & $P$-value \\
\hline$\overline{\text { Age Mean } \pm S D}$ & $70.17 \pm 12.17$ & $69.21 \pm 12.18$ & $70.64 \pm 12.16$ & 0.20 \\
\hline Sex, Female (\%) & $270(50.7)$ & $90(51.4)$ & $180(50.3)$ & 0.80 \\
\hline Dol, hours Mean \pm SD & $49.14 \pm 27.63$ & $47.12 \pm 29.07$ & $50.12 \pm 26.88$ & 0.24 \\
\hline $\mathrm{P}_{\mathrm{A}} \mathrm{O}_{2}$ Mean $\pm \mathrm{SD}$ & $228.54 \pm 24.30$ & $225.83 \pm 23.17$ & $229.86 \pm 24.75$ & 0.07 \\
\hline $\mathrm{P}_{\mathrm{a}} \mathrm{O}_{2}$ Mean $\pm \mathrm{SD}$ & $94.15 \pm 3.30$ & $93.21 \pm 3.89$ & $94.62 \pm 2.87$ & 0.20 \\
\hline $\mathrm{S}_{\mathrm{p}} \mathrm{O}_{2}$ Mean $\pm \mathrm{SD}$ & $94.13 \pm 1.69$ & $94.05 \pm 1.60$ & $94.17 \pm 1.75$ & 0.46 \\
\hline $\mathrm{pH}$ Mean \pm SD & $7.41 \pm 0.06$ & $7.40 \pm 0.06$ & $7.42 \pm 0.06$ & 0.07 \\
\hline $\mathrm{P}_{\mathrm{a}} \mathrm{CO}_{2}$ Mean $\pm \mathrm{SD}$ & $45.41 \pm 3.77$ & $44.71 \pm 4.36$ & $45.75 \pm 3.39$ & 0.09 \\
\hline $\mathrm{F}_{\mathrm{i}} \mathrm{O}_{2}$ Mean $\pm \mathrm{SD}$ & $27.61 \pm 2.85$ & $27.6 \pm 3.12$ & $27.61 \pm 2.72$ & 0.96 \\
\hline Hgb Mean \pm SD & $11.19 \pm 1.52$ & $10.86 \pm 1.63$ & $11.35 \pm 1.43$ & $<0.001$ \\
\hline $\mathrm{P} / \mathrm{F}$ Mean $\pm \mathrm{SD}$ & $344.76 \pm 38.28$ & $342.09 \pm 41.79$ & $346.07 \pm 36.42$ & 0.26 \\
\hline $\mathrm{P}_{\mathrm{A}} / \mathrm{F}$ Mean $\pm \mathrm{SD}$ & $837.19 \pm 126.70$ & $828.94 \pm 127.32$ & $841.23 \pm 126.37$ & 0.29 \\
\hline$S / F$ Mean $\pm S D$ & $344.39 \pm 34.16$ & $344.78 \pm 36.22$ & $384.00 \pm 33.21$ & 0.856 \\
\hline Ol Mean \pm SD & $4258.47 \pm 809.76$ & $4281.55 \pm 765.33$ & $4247.19 \pm 831.42$ & 0.65 \\
\hline OSI Mean \pm SD & $4254.35 \pm 796.11$ & $4230.81 \pm 703.39$ & $4265.86 \pm 838.41$ & 0.63 \\
\hline Survival, alive n (\%) & $446(83.7)$ & $150(85.7)$ & $296(82.7)$ & 0.37 \\
\hline
\end{tabular}

Dol means duration of intubation; $\mathrm{P}_{\mathrm{A}} \mathrm{O}_{2}$ means partial pressure of $\mathrm{O}_{2}$ in alveoli; $\mathrm{P}_{\mathrm{a}} \mathrm{O}_{2}$ means partial pressure of $\mathrm{O}_{2}$ in arterial blood; $\mathrm{S}_{\mathrm{p}} \mathrm{O}_{2}$ means peripheral capillary oxygen saturation; $\mathrm{P}_{\mathrm{a}} \mathrm{CO}_{2}$ means partial pressure of $\mathrm{CO}_{2}$ in arterial blood; $\mathrm{F}_{\mathrm{i}} \mathrm{O}_{2}$ means fraction of inspired oxygen; $\mathrm{Hgb}$ means hemoglobin; $\mathrm{S} / \mathrm{F}$ means $\mathrm{S} \mathrm{O}_{2} / \mathrm{FiO}_{2}$ ratio; $\mathrm{P} / \mathrm{F}$ means $\mathrm{P}_{\mathrm{a}} \mathrm{O}_{2} / \mathrm{FiO}_{2}$ ratio; $\mathrm{P}_{\mathrm{A}} / \mathrm{F}$ means $\mathrm{P}_{\mathrm{A}} \mathrm{O}_{2} / \mathrm{FiO}_{2}$ ratio; OI means Oxygen Index; OSI means Oxygen Saturation Index 
Mean duration of post-operative intra-aortic balloon pump support was $67.38 \pm 21.45 \mathrm{~h}$ (P/F 67.29 \pm 16.68 ; S/F $70.00 \pm$ 22.99; $\left.\mathrm{P}_{\mathrm{A}} / \mathrm{F} 64.74 \pm 24.61 ; p=0.71\right)$.

Our data met the criteria only for the PF ratio for mild ARDS (PF 200-300). The mean time between charted $\mathrm{P}_{\mathrm{a}} \mathrm{O}_{2}$ and $\mathrm{S}_{\mathrm{P}} \mathrm{O}_{2}$ pairs was $50.27 \pm 11.65 \mathrm{~s}$ (Derivation $50.21 \pm 12.18$; Validation $50.30 \pm 11.40$ ).

In the derivation cohort, the $\mathrm{S} / \mathrm{F}$ and $\mathrm{P}_{\mathrm{A}} / \mathrm{F}$ ratios could be predicted well from $\mathrm{P} / \mathrm{F}$, described by the linear regression models $\mathrm{S} / \mathrm{F}=71.149+0.8 \mathrm{PF}$ and $\mathrm{P}_{\mathrm{A}} / \mathrm{F}=38.098+2.312 \mathrm{PF}$, respectively. According to the linear regression equation, a
$\mathrm{P} / \mathrm{F}$ ratio of 300 equaled an $\mathrm{S} / \mathrm{F}$ ratio of $311\left(\mathrm{R}^{2} 0.857, \mathrm{~F}\right.$ $1035.742,<0.0001)$ and $a P_{A} / F$ ratio of $732\left(R^{2} 0.576, F\right.$ $234.887,<0.0001)$. The scatter plots for the (S/F vs $\mathrm{P} / \mathrm{F})$ and $\left(\mathrm{P}_{\mathrm{A}} / \mathrm{F}\right.$ vs. $\left.\mathrm{P} / \mathrm{F}\right)$ ratios for the derivation and validation data sets is shown in Figs. 2 and 3 respectively.

The S/F threshold of 311 had $90 \%$ sensitivity, $80 \%$ specificity, LR+ 4.50, LR- 0.13, PPV 98, and NPV 42.1 for the diagnosis of mild ARDS. The $\mathrm{P}_{\mathrm{A}} / \mathrm{F}$ threshold of 732 had $86 \%$ sensitivity, $90 \%$ specificity, LR+ 8.45 , LR- 0.16, PPV 98.9, and NPV 36 for the diagnosis of mild ARDS. S/F had excellent discrimination ability
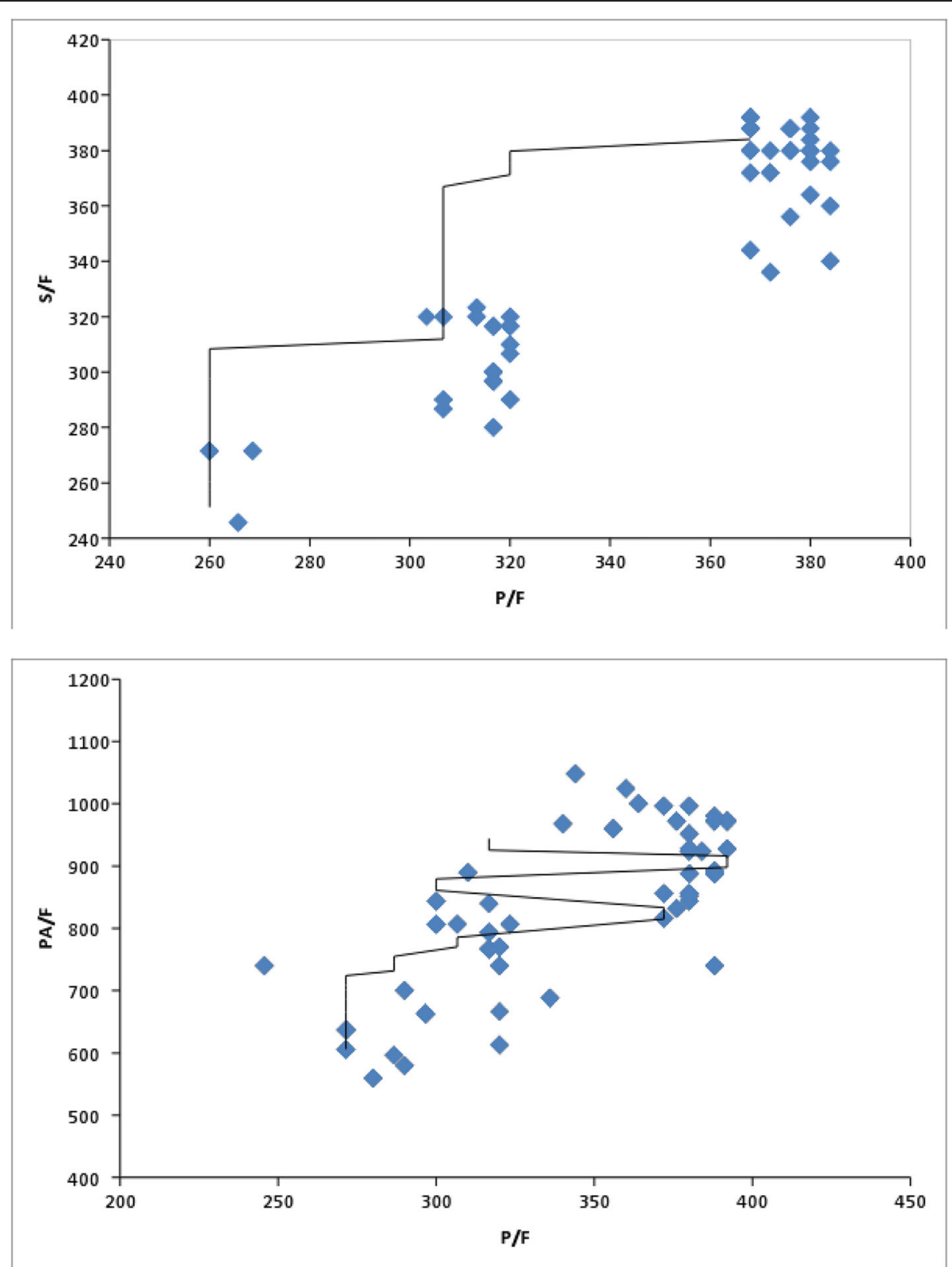

Fig. 2 Scatter plots for $S / F$ vs. P/F ratios (top) and $P_{A} / F$ vs. P/F ratios (bottom) for the derivation data set. The $S / F$ vs. P/F line of best fit equals (S/ $F=71.149+0.8 \mathrm{PF}) ;(P<0.0001 ; r=0.926) ;$ whereas the $P_{A} / F$ vs. $P / F$ line of best fit equals $\left(P_{A} / F=38.098+2.312 P F\right) ;(P<0.0001 ; r=0.759)$ 


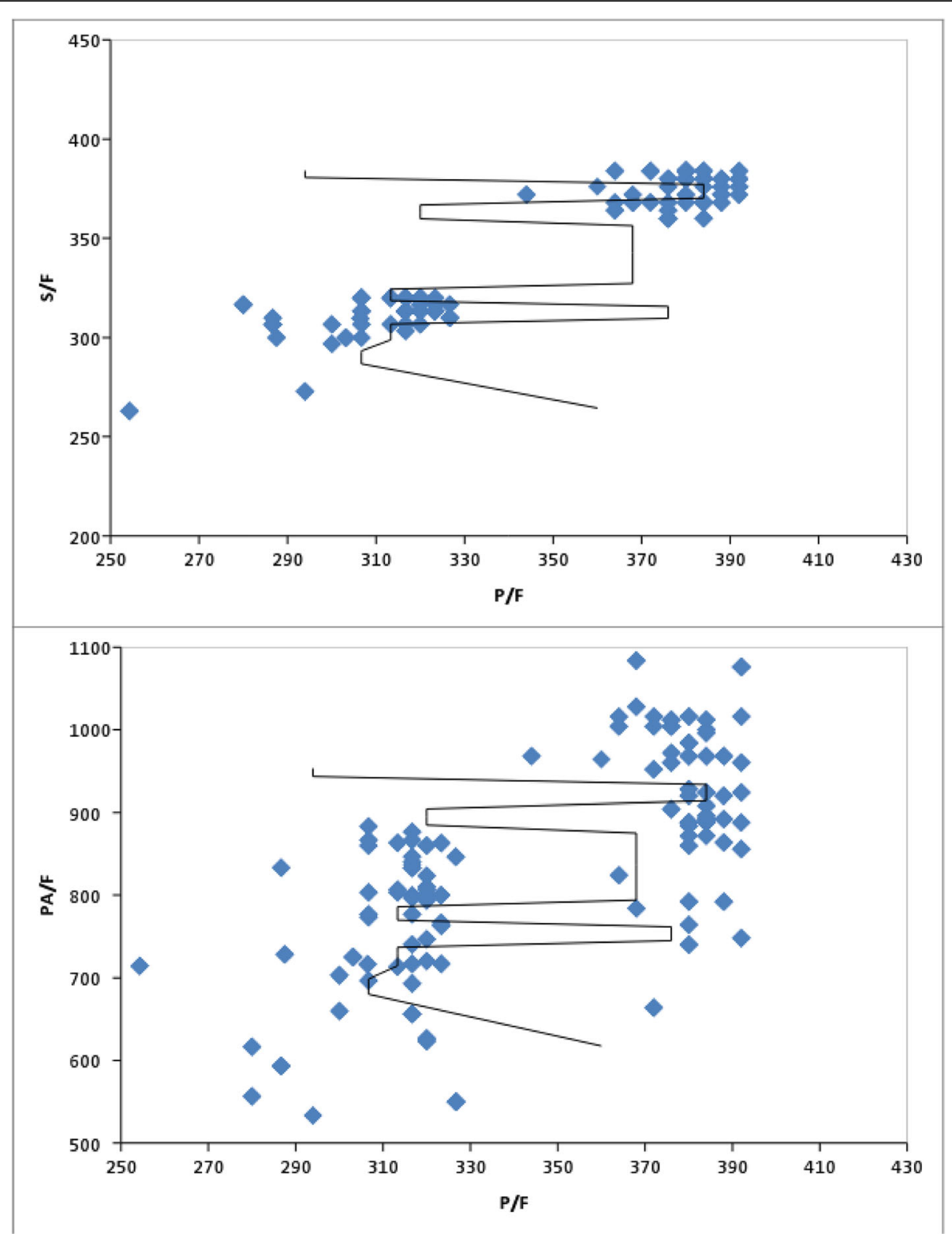

Fig. 3 Scatter plots for $S / F$ vs. $P / F$ ratios (top) and $P_{A} / F$ vs. $P / F$ ratios (bottom) for the validation data set. The $S / F$ vs. P/F line of best fit equals (S/ $F=43.309+0.869 P F) ;\left(R^{2} 0.909 ; F 3565.427 ;<0.0001\right) ;(<0.0001 ; r=0.954) ;$ whereas the $P_{A} / F$ vs. $P / F$ line of best fit equals $(P A F R=-1.537+$ 2.435PFR); $\left(R^{2}\right.$ 0.493; F 345.762; $\left.<0.0001\right) ;(<0.0001 ; r=0.702)$

for mild ARDS (AUC $\pm \mathrm{SE}=0.92 \pm 0.017 ; \quad 95 \% \quad \mathrm{CI}$ 0.889 to 0.947 ) as did $\mathrm{P}_{\mathrm{A}} / \mathrm{F}$ for mild ARDS (AUC \pm $\mathrm{SE}=0.915 \pm 0.018 ; 95 \%$ CI 0.881 to0.942).

\section{Discussion}

ARDS manifests as acute refractory hypoxemia, bilateral pulmonary infiltrates and non-cardiogenic pulmonary edema, and has a very high mortality [23]. The Berlin Criteria (2012) [13, 24] defines ARDS by 4 main characteristics: (1) Timing within 1 week of known clinical insult or new or worsening symptoms;

(2) Chest imaging with bilateral opacities not fully explained by effusions, lobar/lung collapse, or nodules; (3) Origin of edema not fully explained by cardiac failure or fluid overload; and Oxygen impairment defined as mild $(200 \mathrm{mmHg}<\mathrm{P} / \mathrm{F} \leq 300 \mathrm{mmHg}$, with PEEP or CPAP $\left.\geq 5 \mathrm{cmH}_{2} \mathrm{O}\right)$, moderate $(100 \mathrm{mmHg}$ $<\mathrm{P} / \mathrm{F} \leq 200 \mathrm{mmHg}$, with PEEP $\geq 5 \mathrm{cmH}_{2} \mathrm{O}$ ), or severe $\left(\mathrm{P} / \mathrm{F} \leq 100 \mathrm{mmHg}\right.$, with PEEP $\left.\geq 5 \mathrm{cmH}_{2} \mathrm{O}\right)$.

It is known, however, that ARDS criteria may be met in post-op CABG patients in the absence of true ARDS. Thus, a need exists to improve diagnostic specificity [25]. Owing to concerns about anemia, excessive phlebotomy, and a movement to minimally invasive 
approaches, we investigated whether non-invasive indices of oxygenation $\left(\mathrm{S} / \mathrm{F}, \mathrm{P}_{\mathrm{A}} / \mathrm{F}\right)$ performed equal to or better than $\mathrm{P} / \mathrm{F}$ in identifying post-operative ARDS in patients post-CABG.

Despite wide recognition of the high morbidity and mortality associated with ARDS, few interventions have been observed to decrease either. One reason for this may be late or delayed diagnosis, rendering the S/F ratio a rapid, convenient, and useful diagnostic tool. A study by of 1742 matched measurements of $\mathrm{S}_{\mathrm{p}} \mathrm{O}_{2}$ and $\mathrm{P}_{\mathrm{a}} \mathrm{O}_{2}$ in adult patients undergoing general anesthesia sought to identify a correlation between the S/F and P/F ratios by incorporating the $\mathrm{S} / \mathrm{F}$ into the respiratory component of the SOFA score and found that both predicted similar outcomes [26]. Results were less convincing in the pediatric population, where only a weak correlation between $\mathrm{S} / \mathrm{F}$ and $\mathrm{P} / \mathrm{F}$ was noted in children with acute lung injury (age 1 month to 18 years) [27]. In an analysis of patients from the ARDS Network, S/F ratios of 235 and 315 correlated with PF ratios of 200 and 300 respectively [20]. Our findings were in keeping with prior reports that $\mathrm{S} / \mathrm{F}$ ratios correlate with $\mathrm{P} / \mathrm{F}$ ratios $[18,28-30]$, supporting our finding that an $\mathrm{S} / \mathrm{F}$ ratio of 311 correlates with a P/F of 300 (Sensitivity $90 \%$, Specificity $80 \%$ ).

Advantages of using the $\mathrm{S} / \mathrm{F}\left(\mathrm{aka} \mathrm{S}_{\mathrm{p}} \mathrm{O}_{2} / \mathrm{F}_{\mathrm{i}} \mathrm{O}_{2}\right)$ ratio in the diagnosis of ARDS are many. It may allow for real-time monitoring, is dynamic allowing for rapid identification of oxygenation changes, and may allow for earlier diagnosis. Additionally, it allows for a decrease in phlebotomy, blood loss, fewer skin breaks, fewer vascular punctures, and less associated pain. Furthermore, it is affordable, time saving, and already standard practice in most ICUs [31, 32].

Despite obvious advantages and utility of S/F, its use may not be appropriate for all situations. For example, some factors that limit the accuracy of pulse oximetry include methemoglobinemia, oximeter location, cardiogenic shock and temperature [30]. Other factors to consider include patient position andcognitive status (eg. delirium, agitation), which may alter measurements due to movement. Therefore, to decrease the risk of error and resultant misdiagnosis, a steady wave form as described in our study should be used.

\section{Conclusion}

In conclusion, cardiac surgery with cardiopulmonary bypass elicits a systemic inflammatory response that increases the risk for ARDS. $\mathrm{P}_{\mathrm{a}} \mathrm{O}_{2}$ and $\mathrm{S}_{\mathrm{a}} \mathrm{O}_{2}$ correlated in the diagnosis of ARDS, with a P/F of 300 correlating to an S/F of 311 (Sensitivity 90\%, Specificity $80 \%$ ). The S/F ratio may allow for early real-time rapid identification of ARDS, while decreasing the cost, phlebotomy, blood loss, pain, skin breaks, and vascular punctures associated with ABG measurements.

\section{Abbreviations}

ABG: Arterial blood gas; ARDS: Acute respiratory distress syndrome;

AUC: Area under the curve; CABG: Coronary artery bypasses graft;

CAD: Coronary artery disease; CVD: Cardiovascular disease; $\mathrm{F}_{i} \mathrm{O}_{2}$ : Fraction of inspired oxygen; LVEF: Left ventricular ejection fraction; $\mathrm{P} / \mathrm{F}: \mathrm{P}_{\mathrm{a}} \mathrm{O}_{2} / \mathrm{FiO}_{2} ; \mathrm{P}_{\mathrm{A}}$ l $\mathrm{F}: \mathrm{P}_{\mathrm{A}} \mathrm{O}_{2} / \mathrm{FiO}_{2} ; \mathrm{P}_{\mathrm{A}} \mathrm{O}_{2}$ : Partial pressure of $\mathrm{O}_{2}$ in alveoli; $\mathrm{P}_{2} \mathrm{O}_{2}$ : Partial pressure of $\mathrm{O}_{2}$ in arterial blood; PBW: Predicted body weight; $\mathrm{ROC}$ : Receiver operating characteristic; S/F: $\mathrm{S}_{\mathrm{P}} \mathrm{O}_{2} / \mathrm{FiO}_{2}$; SIRS: Systemic inflammatory response syndrome; $\mathrm{S}_{\mathrm{p}} \mathrm{O}_{2}$ : Peripheral capillary oxygen saturation; $\mathrm{V}_{\mathrm{T}}$ : Tidal volume

\section{Acknowledgements}

We thank the Loghman Clinical Research Development Center, Loghman Hakim Hospital, and Shahid Beheshti University of Medical Sciences in Tehran, Iran for methodological, logistical, and limited financial support.

\section{Funding}

This research did not receive any specific grant from funding agencies in the public, commercial, or not-for-profit sectors.

\section{Availability of data and materials}

All data generated or analyzed during this study are included in this article.

\section{Author's contributions}

Project conception, design, implementation and data acquisition was performed by FRB, AVA, BF, RG, SS, SH, SMMM, MK and MAKK. Data analysis was performed by AVA and ACM. Manuscript writing and revision was performed by ACM, AT, and AVA. All authors read and approved the final manuscript.

\section{Author's information}

Dr. Miller is residency trained in both Emergency Medicine and Internal Medicine from the State University of New York (SUNY) Downstate Medical Center in Brooklyn, NY. He then completed fellowships in Pulmonary Medicine at the University of Pittsburgh Medical Center in Pittsburgh, PA, followed by Critical Care Medicine at the National Institutes of Health in Bethesda, MD. He is currently Clinical Associate Professor and Chief, Division of Research in the Department of Emergency Medicine at East Carolina University Brody School of Medicine. He is highly published and experienced in the clinical investigation of respiratory failure, resuscitation, and shock. Dr. Miller is Director of the MORZAK Collaborative through which he has cultivated a strong working relationship with investigators in numerous countries. In the current project, Dr. Miller worked with investigators in Iran to investigate whether non-invasive oxygenation indicies may be used to diagnose ARDS in post-op patient's following CABG surgery.

\section{Ethics approval and consent to participate}

The protocol was approved by the investigational review board at Baqiyatallah University of Medical Sciences. Consent was required and covered both study participation and publication of findings. Informed consent was required prior to cardiac arrest event and could be provided by the patient, legal guardian, or healthcare surrogate.

\section{Consent for publication}

The informed consent included permission to present and publish de-identified results.

\section{Competing interests}

The authors declare that they have no competing interests.

\section{Publisher's Note}

Springer Nature remains neutral with regard to jurisdictional claims in published maps and institutional affiliations.

\section{Author details}

${ }^{1}$ Anesthesia and Critical Care Department, Hamadan University of Medical Sciences, Hamadan, Iran. ${ }^{2}$ Trauma Research Center, Nursing Faculty, Baqiyatallah University of Medical Sciences, Tehran, Iran. ${ }^{3}$ Tracheal Diseases Research Center, Anesthesia and Critical Care Department, Masih Daneshvari Hospital, Shahid Beheshti University of Medical Sciences, Tehran, Iran.

${ }^{4}$ Anesthesiology Research Center, Anesthesia and Critical Care Department, Loghman Hakim Hospital, Shahid Beheshti University of Medical Sciences, 
Tehran, Iran. ${ }^{5}$ Anesthesia and Critical Care Department, Alborz University of Medical Sciences, Karaj, Iran. ${ }^{6}$ Anesthesiology Research Center, Anesthesia and Critical Care Department, Modares Hospital, Shahid Beheshti University of Medical Sciences, Tehran, Iran. ${ }^{7}$ Anesthesiology Research Center, Anesthesia and Critical Care Department, Khatam-o-anbia Hospital, Zahedan University of Medical Sciences, Zahedan, Iran. ${ }^{8}$ Anesthesiology Research Center, Anesthesia and Critical Care Department, Taleghani Hospital, Shahid Beheshti University of Medical Sciences, Tehran, Iran. ${ }^{9}$ Department of Internal Medicine, Vident Medical Center, East Carolina University Brody School of Medicine, Greenville, NC, USA. ${ }^{10}$ Department of Emergency Medicine, Vident Medical Center, East Carolina University Brody School of Medicine, 600 Moye Blvd, Greenville, NC 27834, USA.

Received: 6 July 2018 Accepted: 5 November 2018

Published online: 27 November 2018

\section{References}

1. Vahedian-Azimi A, Sadeghi M, Movafegh A, Zanjani RS, Hasani D, Salehmoghaddam A, et al. The relationship between perceived stress and the top five heart disease characteristics in patients with myocardial infarction. J Zanjan Univ Med Sci. 2012;20(78):100-12.

2. Mathers $C D$, Loncar D. Projections of global mortality and burden of disease from 2002 to 2030. PLoS medicine. 2006;3(11):e442.

3. Roth G, Huffman M, Moran A, Feigin V, Mensah G, Naghavi M, et al. Global and Regional Patterns in Cardiovascular Mortality From 1990 to 2013. Circulation. 2015;132(17):1667-78.

4. Laslett LJ, Alagona P, Clark BA, Drozda JP, Saldivar F, Wilson SR, et al. The worldwide environment of cardiovascular disease: prevalence, diagnosis, therapy, and policy issues: a report from the American College of Cardiology. J Am Coll Cardiol. 2012;60(25 Suppl):1.

5. Naghavi M, Wang H, Lozano R, Davis A, Liang X, Zhou M, et al. Global, regional, and national age-sex specific all-cause and cause-specific mortality for 240 causes of death, 1990-2013: a systematic analysis for the Global Burden of Disease Study 2013. Lancet. 2015;385(9963):117-71.

6. Michalopoulos A, Tzelepis G, Dafni U, Geroulanos S. Determinants of Hospital Mortality After Coronary Artery Bypass Grafting. Chest. 1999;115(6): 1598-603.

7. Michalopoulos A, Stavridis G, Geroulanos S. Severe Sepsis in Cardiac Surgical Patients. Eur J Surg. 1998;164(3):217-22.

8. Tuman KJ, McCarthy RJ, March RJ, Najafi H, Ivankovich AD. Morbidity and duration of ICU stay after cardiac surgery. A model for preoperative risk assessment. Chest. 1992;102(1):36

9. Michalopoulos A, Prapas S, Falagas ME. The incidence of adult respiratory distress syndrome in patients undergoing off-pump coronary artery bypass grafting surgery. Eur J Anaesthes. 2006;23(1):80.

10. Milot J, Perron J, Lacasse Y, Létourneau L, Cartier PC, Maltais F. Incidence and Predictors of ARDS After Cardiac Surgery. Chest. 2001;119(3):884-8.

11. Christenson JT, Aeberhard J-M, Badel P, Pepcak F, Maurice J, Simonet F, et al. Adult respiratory distress syndrome after cardiac surgery. Cardiovasc Surg. 1996:4(1):15-21.

12. Kaul TK, Fields BL, Riggins LS, Wyatt DA, Jones CR, Nagle D. Adult respiratory distress syndrome following cardiopulmonary bypass: incidence, prophylaxis and management. J Cardiovasc Surg. 1998;39(6):777-81.

13. Ranieri VM, Rubenfeld GD, Thompson BT, Ferguson ND, Caldwell E, Fan E, et al. Acute Respiratory Distress Syndrome: The Berlin Definition. JAMA. 2012; 307(23):2526-33.

14. Faul F, Erdfelder E, Lang A, Buchner A. GPower 3: A flexible statistical power analysis program for the social, behavioral, and biomedical sciences. Behavior Research Methods. 2007;39(2):175-91.

15. Faul F, Erdfelder E, Buchner A, Lang A. Statistical power analyses using GPower 3.1: Tests for correlation and regression analyses. Behavior Research Methods. 2009:41(4):1149-60

16. Ware L. Prognostic determinants of acute respiratory distress syndrome in adults: Impact on clinical trial design. Crit Care Med. 2005;33(3 Suppl):S222.

17. DesPrez K, McNeil JB, Wang C, Bastarache JA, Shaver CM, Ware LB. Oxygenation saturation index predicts clinical outcomes in ARDS. Chest. 2017;152(6):1151-8.

18. Rice TW, Wheeler AP, Bernard GR, Hayden DL, Schoenfeld DA, Ware LB. Comparison of the Spo2/Fio2 Ratio and the Pao2/Fio2 Ratio in Patients with Acute Lung Injury or ARDS. Chest. 2007;132(2):410-7.
19. von Elm E, Altman DG, Egger M, Pocock SJ, Gøtzsche PC, Vandenbroucke JP. The Strengthening the Reporting of Observational Studies in Epidemiology (STROBE) statement: guidelines for reporting observational studies. Lancet. 2007:370(9596):1453-7.

20. Miller RD, Eriksson L, Fleisher L, Wiener-Kronish J, Cohen N, Young W. Miller's Anesthesia. 8th ed. Philadelphia: Elsevier Churchill Livingstone; 2015.

21. Nagaraj S, McClain L, Zhou D, Biswal S, Rosenthal E, Purdon P, et al. Automatic Classification of Sedation Levels in ICU Patients Using Heart Rate Variability. Critical Care Medicine. 2016:44(9):e789.

22. Nagaraj S, Biswal S, Boyle E, Zhou D, McClain L, Bajwa E, et al. PatientSpecific Classification of ICU Sedation Levels from Heart Rate Variability. Critical Care Medicine. 2017;45(7):e690.

23. Ware LB, Matthay MA. The Acute Respiratory Distress Syndrome. N Engl J Med. 2000;342(18):1334-49.

24. Ferguson N, Fan E, Camporota L, Antonelli M, Anzueto A, Beale R, et al. The Berlin definition of ARDS: an expanded rationale, justification, and supplementary material. Intens Care Med. 2012;38(10):1573-82.

25. Vakili M, Shirani S, Paknejad O, Yousefshahi F. Acute Respiratory Distress Syndrome diagnosis after coronary artery bypass: comparison between diagnostic criteria and clinical picture. Acta Med Iran. 2015;53(1):51-6.

26. Pandharipande $P$, Shintani A, Hagerman H, St Jacques P, Rice T, Sanders N, et al. Derivation and validation of $\mathrm{Spo} 2 / \mathrm{Fio} 2$ ratio to impute for $\mathrm{Pao} 2 / \mathrm{Fio} 2$ ratio in the respiratory component of the Sequential Organ Failure Assessment score. Crit Care Med. 2009:37(4):1317-21.

27. Laila D, Yoel C, Hakimi H, Lubis M. Comparison of SpO2/FiO2 and PaO2/FiO2 ratios as markers of acute lung injury. Paediatr Indones. 2017:57(1):30-4.

28. Jensen LA, Onyskiw JE, Prasad NGN. Meta-analysis of arterial oxygen saturation monitoring by pulse oximetry in adults. Heart Lung. 1998;27(6): 387-408

29. Perkins GD, McAuley DF, Giles S, Routledge H, Gao F. Do changes in pulse oximeter oxygen saturation predict equivalent changes in arterial oxygen saturation? Crit Care. 2003 Aug;7(4):R71.

30. Webb RK, Ralston AC, Runciman WB. Potential errors in pulse oximetry. II. Effects of changes in saturation and signal quality. Anaesthesia. 1991 Mar; 46(3):207-12.

31. Jubran A, Tobin MJ. Reliability of Pulse Oximetry in Titrating Supplemental Oxygen Therapy in Ventilator-Dependent Patients. Chest. 1990;97(6):1420-5.

32. Jubran A. Pulse Oximetry. Intens Care Med. 2004;30(11):2017-20.
Ready to submit your research? Choose BMC and benefit from:

- fast, convenient online submission

- thorough peer review by experienced researchers in your field

- rapid publication on acceptance

- support for research data, including large and complex data types

- gold Open Access which fosters wider collaboration and increased citations

- maximum visibility for your research: over $100 \mathrm{M}$ website views per year

At BMC, research is always in progress.

Learn more biomedcentral.com/submissions 